during endoscopic retrograde cholangiography. The first results of intraductal pressure measurements during endoscopic cannulation have been published. ${ }^{12}{ }^{13}$ The return of laboratory values to normal and the disappearance of the complaints after papillotomy verified retrospectively our diagnosis of papillary stenosis.

The contraindications for endoscopic papillotomy are identical to those for the similar surgical procedure-that is, (a) long stenoses of the bile duct; $(b)$ a papilla situated at the edge of a duodenal diverticulum; and $(c)$ when the position of the papillotome in the common bile duct is not completely certain. In the case of very large and impacted stones papillotomy may relieve obstruction but one must warn against enforced extraction.

Ductal stones smaller than $10 \mathrm{~mm}$ in diameter will pass into the duodenum spontaneously after papillotomy (fig 7). We tried to remove larger stones immediately after the incision was made to prevent them getting wedged into the ampulla. Manipulation must be done with great care as bile duct perforations with the Dormia basket and Fogarthy catheter ${ }^{11}$ have been described.

Initially we favoured removing all stones immediately after papillotomy, and we successfully removed gall stones in this way in 11 cases - a single stone from eight patients and two to four stones from three patients. The Dormia catheter used for this purpose, however, is far from an ideal tool. It often does not open completely or it may slide out between the stone and wall of the duct. To try and repeat the procedure is time-consuming and increases considerably the exposure to radiation. An instrument to crush the stones intraductally is needed. In later patients we found that after a papillotomy of adequate length even larger calculi passed spontaneously (fig 8). Recently we have attempted mechanical stone extraction only if a residual stone is still present at the follow-up examination a week after papillotomy.
We failed to remove the stones in 6 patients: in three of these two or three stones were removed and one could not be mobilised. It is remarkable that the jaundice in four patients with retained stones also disappeared after papillotomy. A free bile flow was observed once papillary stenosis was relieved, despite the residual stone. Apart from the inadequacy of the extractor the causes of failure were: a stone tightly adhering to the wall in two cases, a very large stone in two cases, and restenosis of the papillotomy opening in two cases.

A successful papillotomy and extraction of stones results in a complete cure and a failed procedure does not increase the difficulty of open surgery later. In our experience endoscopic papillotomy and stone extraction is relatively safe, and in a high proportion of cases it is effective in treating extrahepatic obstructive jaundice due to gall stones and papillary stenosis.

\section{References}

${ }^{1}$ Dardinsky, V J, fournal of Anatomy, 1934/35, 69, 469.

${ }^{2}$ Hess, W, Surgery of the Biliary Passages and the Pancreas. Princeton, Van Nostrand, 1965.

${ }^{3}$ Kawai, K, et al, Fournal of Kyoto Prefectural University of Medicine, 1973, 82, 353.

4 Bünte, H, et al, Deutsche medizinische Wochenschrift, 1974, 99, 2312.

${ }^{5}$ Demling, L, et al, Deutsche medizinische Wochenschrift, 1974, 99, 2255.

6 Classen, M, Medical Tribune, 1973, no 27, p 1.

${ }^{7}$ Classen, M, and Demling, L, Deutsche medizinische Wochenschrift, 1974, 99, 496.

${ }^{8}$ Cotton, P B, et al, Lancet, 1972, 1, 53.

${ }^{9}$ Safrany, L, et al, Gastroenterological Endoscopy, 1973, 19, 163.

10 Safrany, L, Acta Gastro-enterologica Belgica, 1973, 36, 711.

11 Henzel, J H, Blessing, W D, and Deweese, M D, Archives of Surgery, $1971,102,218$

12 Nebel, O T, Gastroenterology, 1974, 66, 818.

13 Vondrasek, P, Eberhardt, G, and Classen, M, Innerere Medizin, 1974 $3,188$.

\title{
Metal sensitivity in patients with joint replacement arthroplasties
}

\author{
M K D BENSON, P G GOODWIN, JONATHAN BROSTOFF
}

British Medical fournal, 1975, 4, 374-375

\section{Summary}

A high incidence of unexpected metal sensitivity was found in patients with metal-to-metal (McKee) hip arthroplasties. Patients with metal-to-plastic (Charnley) prostheses had no greater incidence of metal sensitivity than a control group awaiting operation. If metal sensitivity does occur loosening of the prosthesis may be a complication

\section{Introduction}

Sensitivity of patients to the constituents of implants used in orthopaedic surgery-namely, cobalt, chromium, and nickel-

\section{Middlesex Hospital, London W1N 8AA}

M K D BENSON, FRCS, senior orthopaedic registrar

P G GOODWIN, MRCP, senior registrar, department of dermatology

Department of Immunology, Middlesex Hospital Medical School, London W1P 9PG

JONATHAN BROSTOFF, MRCP, MRCPATH, senior lecturer has been increasingly recognised. ${ }^{1-3}$ The absorption of metal into hair and blood and its excretion in urine is increased after hip replacement arthroplasties, particularly when metal-tometal bearings are used. ${ }^{4}$ Similarly, blood methylmethacrylate levels are raised when acrylic cement is used. ${ }^{5}$ This increased absorption may lead to sensitivity which can be seen as eczematous dermatitis or urticaria. ${ }^{2}$ It has been suggested that metal sensitivity may lead to loosening of metal-on-metal hip prostheses. $^{3}$ The exact incidence and importance of sensitivity after joint replacement remains in doubt and we carried out a study to attempt to resolve these problems.

\section{Patients and methods}

Seventy-two patients who had undergone total hip replacement at the Middlesex Hospital from 1968 to 1972 were examined. A control group was formed by 33 patients awaiting total hip replacement. The patients were well matched for age, the average being 67 years in both groups. The male to female ratio was $1: 2$. Osteoarthritis was the commonest reason for replacement arthroplasty though three of the control group and eight of the test group suffered from rheumatoid arthritis. Thirty-nine patients received a Charnley prosthesis, 32 a McKee, and one a Stanmore. As some replacement arthroplasties were bilateral the 72 patients had a total of 91 protheses. The Charnley prostheses had been implanted for a mean of $4 \cdot 2$ years and the McKee prostheses for a mean of $5 \cdot 2$ years. The Charnley and Stanmore 
prostheses are metal on high density polyethylene joints whereas the McKee prostheses are metal on metal.

All patients were asked whether they had a history of allergy to metal or plastic, emphasising particularly any skin reaction. We specifically sought information about occupational factors such as exposure to metals and plastics and work in either the tanning or cement industries, where there is contact with chrome salts. Patients were also asked about reactions to acrylic dentures. ${ }^{6}$ In each patient an objective and subjective assessment of residual hip pain and function was made. Discomfort was graded as none, mild, moderate, or severe. Function was graded as good, moderate, or poor. Any postoperative complication such as infection or loosening was noted.

Patients were patch tested in the standard manner ${ }^{7}$ with various substances including the metal constituents of replacement prostheses together with acrylic cement, chemical activators and inhibitors, the radio-opaque barium marker, and formaldehyde used for sterilisation. The following substances were used: potassium dichromate $0.5 \%$, cobalt chloride $2 \%$, nickel sulphate $5 \%$, formaldehyde $2 \%$, barium sulphate $10 \%$, monomer (methylmethacrylate) $1 \%$, polymer (polymethylmethacrylate) $10^{\circ}$, hydroquinone $0.2 \%$, benzoyl peroxide $5 \%$, and a control. The patch tests were read after 72 hours and again after one week.

\section{Results}

The relation between the history of metal sensitivity, patch test result, and type of prosthesis used is shown in table I. The incidence of positive results in the McKee group was $28 \%$ whereas among those who had Charnley protheses (metal to plastic) it was $2 \cdot 6 \%$. This was a highly significant difference $(P=0 \cdot 003$, Fisher's exact test). Several patients gave a history of metal sensitivity that was not confirmed by patch testing. The single patient in the Charnley group who was positive did, however, give a history of metal sensitivity.

TABLE I-Relation between history of metal sensitivity, patch test result, and type of prosthesis

\begin{tabular}{l|c|c|c}
\hline & Controls & Charnley group & McKee group \\
\hline $\begin{array}{c}\text { No }(\%) \text { with history of sensitivity } \\
\text { No }(\%) \text { positive on patch test } . .\end{array}$ & $\begin{array}{c}4(12 \cdot 1) \\
3(9 \cdot 1)\end{array}$ & $\begin{array}{c}2(5 \cdot 1) \\
1(2 \cdot 6)\end{array}$ & $\begin{array}{l}4(12 \cdot 5) \\
9(28 \cdot 1)\end{array}$ \\
\hline
\end{tabular}

Hypersensitivity was found only to the metal constituents of the hip replacements, and no patient in either group showed any other sensitivity. Patients who had received bilateral arthroplasties did not show an increased incidence of metal sensitivity. In the control group two patients $(6.1 \%)$ were positive to nickel alone and one $(3 \%)$ to nickel and cobalt in combination. Only one patient $(2.6 \%)$ with a Charnley prothesis was positive (to nickel). But of patients with McKee hip replacements one $(3 \cdot 1 \%$ ) was sensitive to nickel alone, two $(6.3 \%)$ to nickel and cobalt in combination, three $(9.4 \%)$ to cobalt alone, and, surprisingly, three $(9 \cdot 4 \%)$ to chromium alone.

TABLE II-Relation between complications of hip replacement and patch-test responses

\begin{tabular}{l|c|c|c|c|c|c}
\hline & \multicolumn{2}{|c|}{ Failed prosthesis } & \multicolumn{3}{|c|}{ Residual pain } & \\
\cline { 2 - 6 } & Infection & Loosening & None & Mild & Moderate & Severe \\
\hline $\begin{array}{c}\text { Patch-test positive } \\
\text { Patch-test negative }\end{array}$ & 0 & 2 & 5 & 4 & 3 & 1 \\
\hline
\end{tabular}

Table II shows the relation between the complications after total hip replacement and the patch-test responses of the recipient. Two Charnley and two McKee hips became infected, but none of these patients gave positive reactions on patch tests. Two hip prostheses failed because of loosening of the prosthesis. Both of these were in the McKee group and both patients gave positive reactions to chromium alone. This association between metal sensitivity and loosening was significant $(P=0.001$, Fisher's exact test). Metal sensitivity was not related to the presence or absence of postoperative discomfort.
In none of the patients examined was there evidence of occupational exposure to metals, and, in particular, none of the three patients with chromate sensitivity had worked in the tanning or cement industries. There was no correlation between age, sex, or pathological hip condition and the development of metal sensitivity.

\section{Discussion}

We found a high incidence of unexpected metal allergynamely, to cobalt and chromium-in patients who had received a metal-to-metal (McKee) hip prosthesis. By contrast, the incidence of metal sensitivity in those with a Charnley prosthesis was no higher than in the control group.

Metal-to-metal bearings shed many more wear particles, producing local tissue concentrations ten times higher than those found adjacent to metal-to-plastic ones. ${ }^{8}$ Therefore this shedding probably provides the primary stimulus for sensitisation. The incidence of metal sensitivity in the general population is unknown. When surveys have been carried out, however, the common positive reaction is to nickel alone or to nickel and cobalt in combination ${ }^{9}$ because cobalt is a natural contaminant of nickel. Sensitivity is usually acquired by wearing metal suspenders and jewellery in contact with the skin and is therefore commoner in women. Acquired sensitivity to cobalt alone is relatively less common, as is sensitivity to chromium, which may, however, be induced after prolonged contact with cement or leather tanned with dichromate. Although one case of sensitisation of a surgeon's hands to methylmethacrylate has been reported ${ }^{10}$ we found no positive reactions to plastic or other materials used during hip replacement.

Our findings suggest that metal particles containing relatively high concentrations of both cobalt and chromium sensitise the patient. It is of interest that of two patients who developed prosthetic loosening both were sensitive to chromium, in contrast to the patients reported by Evans $e t$ al, in whom cobalt was implicated. Although these results imply that loosening is associated with metal sensitivity there were too few patients with loosening in our small series to suggest that chromium is more likely to be associated with loosening than the other metals. We found no relation between metal sensitivity and postoperative infection or residual discomfort not due to loosening.

Our results suggest that there is a relation between loosening and metal sensitivity in patients who have received metal-tometal prostheses. It therefore seems advisable to use Charnley or other forms of metal-to-plastic prostheses in preference to metal-to-metal ones.

We are indebted to Dr F R Bettley and Mr D R Sweetnam for their advice and encouragement. Jonathan Brostoff is supported by the Medical' Research Council.

Reprint requests should be sent to P G Goodwin.

\section{References}

${ }^{1}$ Laugier, P, and Foussereau, J, Gazette Médicale de France, 1966, 73, 3409.

2 McKenzie, A W, Aitken, C V E, and Ridsdill-Smith, R, British Medical fournal, 1967, 4, 36.

${ }^{3}$ Evans, E M, et al, fournal of Bone and foint Surgery, 1974, 56B, 626.

4 Coleman, R F, Herrington, J, and Scales, J T, British Medical fournal, $1973,1,527$.

5 Pahuja, K, Lowe, H, and Chand, K, Acta Orthopaedica Scandinavica, $1974,45,737$.

${ }^{6}$ Charnley, J, Acrylic Cement in Orthopaedic Surgery. Edinburgh and London, Livingstone, 1970.

${ }^{7}$ Rook, A, Wilkinson, D S, and Ebling, F J G, (editors), Textbook of Dermatology, vol 2, p 365. Oxford, Blackwell, 1972.

8 Swanson, S A V, Freeman, M A R, and Heath, J C, fournal of Bone and Foint Surgery, 1973, 55B, 759.

${ }^{9}$ Fregert, S, and Rorsman, H, Acta Dermato-Venerologica, 1966, 46, 144.

10 Pegum, J S, and Medhurst, F A, British Medical fournal, 1971, 2, 141. 